\title{
Inequality in Life Lost to Violence in the United States*
}

\author{
Alexander F. Roehrkasse ${ }^{\dagger}$
}

September 22, 2021

\begin{abstract}
This study uses demographic methods to describe ethnoracial and educational inequality in the cumulative risk of homicide death and life lost to violence in the United States. If age-specific homicide rates were to continue at 2018-2019 levels, more than 1 in 19 Black males without a high school diploma would die by homicide. In contrast, 1 in 152 White males without a high school diploma and 1 in 233 Black males with a bachelor's degree would be violently killed. Among Black males without a high school diploma, homicide led to a decrease in life expectancy at ages 15-19 of more than two years. The impact of U.S. violence on the life expectancy of socially marginalized people exceeds the life-expectancy impact on the full U.S. population of all causes of death except heart disease and cancer.
\end{abstract}

Keywords: Homicide; mortality; inequality; race/ethnicity; educational attainment

${ }^{*}$ Direct correspondence to Alexander F. Roehrkasse, Department of Sociology, Duke University, 417 Chapel Dr., Durham, NC 27708. E-mail: afr23@duke.edu.

†Duke University 


\section{Introduction}

Despite significant declines in violent crime over the previous three decades [1], homicide remains a leading cause of death in the United States, particularly among socially and economically marginalized people. In 2018-2019, homicide was the 15th leading cause of death among males, the 5th leading cause among Black males, and the single leading cause among Black males aged 15-44 [2].

The outsize contribution of fatal violence to the diminished life expectancy of young Black males in the United States is well-documented [1, 3, 4], but little is known about socioeconomic variation in homicide mortality $[5,6]$. Recent research has shown that gaps in overall life expectancy by bachelor's degree attainment are now much larger than BlackWhite gaps [7]. This raises questions about the relative scale of educational and ethnoracial inequality in life lost to violence.

Using detailed data on all deaths occurring among U.S. residents in 2018-2019, I use life tables to estimate the cumulative risk of homicide death, decreases in life expectancy due to homicide, and years of potential life lost to homicide. I investigate the scale and impact of homicide at multiple levels of educational attainment, and provide estimates for frequently ignored but acutely affected ethnoracial groups, particularly American Indians and Alaska Natives (AIAN). The results provide the most detailed portrait to date of the relationship between social and economic marginalization and life lost to violence.

\section{Results}

Lifetime risk of homicide death in the United States in 2018-2019 was 0.68\% for males and 0.19\% for females (Fig. 1). Black males without a high school diploma experienced the highest lifetime risk of homicide death (5.4\%), 8.0 times higher than among White males without a high school diploma $(0.67 \%)$ and 13 times higher than among Black males with a bachelor's degree $(0.42 \%)$. Ratios of risk were largest at the margin of college attendance, 
except among AIAN males and females and multiracial females, for whom inequality was greatest at bachelor's degree attainment. Risk of homicide death for AIAN males of all education levels (1.4\%) was half as much as for Black males (2.8\%), but risks for AIAN and Black females were very similar $(0.46 \%$ and $0.47 \%$, respectively).

[Fig. 1 about here.]

Homicide accounted for a significant but unequal proportion of mortality among young people. For Black males without a high school diploma, 39\% of all deaths by ages 30-34 were homicide deaths, compared to $4.8 \%$ of deaths among similarly educated White males and $13 \%$ of deaths among Black males with a bachelor's degree. Cumulative risk of homicide death by ages 30-34 among AIAN males without a high school diploma was high (1.5\%), but was dwarfed by their outlying risk of death from other causes (10\%).

Because homicide was concentrated among younger adults, fatal violence had large effects on life expectancy and years of potential life lost (YPLL) (Table 1). Homicide diminished male life expectancy at ages $15-19$ by .29 years, and female life expectancy by .09 years. Homicide caused a decrease in life expectancy of 2.1 years for Black males without a high school diploma, equivalent to 3,169 YPLL per 100,000. The impact of homicide on the life expectancy of Black males with a bachelor's degree (0.17 years) was comparable to that among White males without a high school diploma (0.19 years). At higher levels of education homicide caused less Black-White inequality in male and female life expectancy. Adjusting for age differences, males without a high school diploma lost only 1.1 times as much life to homicide as those with a high school diploma and no college attendance, but 16 times as much life as those who had attained a bachelor's degree.

[Table 1 about here.]

Case and Deaton [7] have recently documented that educational disparities in life expectancy have grown to exceed racial and ethnic divides. They show, for example, that 
in 2018, gaps in life expectancy between White and Black males were much smaller than gaps between people with and without a bachelor's degree. By similar measures, however, ethnoracial inequality still predominates in life lost to violence. In 2018-2019, homicide widened the gap in life expectancy between White and Black males by 1 year and the gap between males with and without a bachelor's degree by 0.27 years. Similar patterns also held for females. Indeed, racial inequality in fatal violent victimization was so significant that it overwhelmed sexual inequality: at all levels of educational attainment, Black and AIAN females lost more potential life to homicide than White males.

\section{Discussion}

Even before sharp increases in homicides during the COVID-19 pandemic [8], the scale of violent death in the United States was staggering. The annual toll of homicide in 2018-2019 was more than 838,000 years of potential life lost. Using standard valuation of a statistical life-year $(\$ 500,000)[9]$, this amounts to an annual cost of $\$ 419$ billion. By comparison, recent proposals to increase federal funding for community violence intervention programs by $\$ 5.2$ billion [10] seem modest.

The social and economic concentration of homicide victimization means that for marginalized groups, the quantity of life lost to homicide is even more extreme. If group- and causespecific mortality rates continue at 2018-2019 levels, the impact of homicide on the life expectancy of Black males without a bachelor's degree, 1.25 years, will exceed the impact on national life expectancy of each leading cause of death in 2018-2019 except for heart disease (3.47 years) and cancer (2.98 years), with the next leading cause of death, accidents, accounting for a decrease in life expectancy of 1.23 years. Importantly, estimates reported in this study represent only the direct contribution of violence to mortality: because nonfatal violent victimization and indirect exposure to violence adversely affect health [11], the results are likely to represent conservative estimates of life lost to violence. 
The present study shows that despite alarmingly high rates of homicide victimization among AIAN people and people with lower levels of education, Black people in the United States are uniquely subjected to extreme risk of violent death. Scholars have noted that public and scientific attention to preventable death among U.S. Black people falls far short of its scale and impact $[12,13,14]$. Black lives matter, and so research on fatal violence and investment in its prevention must increase [15].

\section{Acknowledgments}

I thank Christopher Wildeman and Sarah Sernaker for helpful comments.

\section{Materials and Methods}

Results are based on mortality multiple cause-of-death files from the National Vital Statistics System (NVSS) and population data from American Community Survey (ACS) five-year samples. I exclude from analysis 291 deaths $(0.0051 \%)$ with missing age information. For 94,146 deaths (1.653\%) with missing education information, I randomly assign values of educational attainment according to the observed distribution among decedents within each age group, sex, ethnoracial group, year, and cause of death (homicide or non-homicide). Results are not meaningfully affected by other, plausible assumptions about nonrandom patterns of missingness.

Homicides are classified by medical examiners and coroners according to the 10th revision of the International Classification of Diseases (ICD). The ICD definition of homicide includes both intentional and negligent fatal injuries but excludes legal intervention deaths, which correspond closely to the Federal Bureau of Investigation's definition of "justifiable homicides." Despite significant ethnoracial inequality in police killings [16], the small scale of legal intervention deaths relative to homicides meant that including legal intervention 
deaths in the analysis had a negligible effect on the overall results.

I group individuals into 5-year age groups and into ethnoracial groups based on separate measures of race and ethnicity. The Hispanic group includes people with multiple or "Other" race; the remaining groups exclude Hispanic, multiracial, and "Other" race people. Demographic information in NVSS data is recorded by funeral directors; in ACS data it is self-reported.

The SI Appendix details the use of multiple-decrement synthetic-cohort life table methods to calculate cumulative risk of homicide and non-homicide death, decreases in life expectancy attributable to homicide, and years of potential life lost to homicide.

\section{Data Availability}

The data are publicly available from the National Center for Health Statistics (https://www.cdc.gov/nchs/data_access/vitalstatsonline.htm) and IPUMS-USA (https://usa.ipums.org/usa/). 


\section{References}

[1] Sharkey P, Friedson M (2019) The Impact of the Homicide Decline on Life Expectancy of African American Males. Demography 56(2):645-663.

[2] Centers for Disease Control and Prevention NCfHS (2020) Underlying Cause of Death 2018-2019 on CDC WONDER Online Database. http://wonder.cdc.gov/ucdicd10.html.

[3] Harper S, Rushani D, Kaufman JS (2012) Trends in the Black-White Life Expectancy Gap, 2003-2008. JAMA 307(21):2257-2259.

[4] Arias E, Heron M, Tejada-Vera B (2013) United States Life Tables Eliminating Certain Causes of Death, 1999-2001. National Vital Statistics Reports 61(9).

[5] Berthelot ER, Brown TC, Thomas SA, Burgason KA (2016) Racial (In)variance, Disadvantage, and Lethal Violence: A Survival Analysis of Black Homicide Victimization Risk in the United States. Homicide Studies 20(2):103-128.

[6] Dare AJ, et al. (2019) Geospatial, racial, and educational variation in firearm mortality in the USA, Mexico, Brazil, and Colombia, 1990-2015: a comparative analysis of vital statistics data. The Lancet Public Health 4(6):e281-e290.

[7] Case A, Deaton A (2021) Life expectancy in adulthood is falling for those without a BA degree, but as educational gaps have widened, racial gaps have narrowed. Proceedings of the National Academy of Sciences 118(11).

[8] Abrams D (2021) City Crime Stats. https://citycrimestats.com/homicides/.

[9] Viscusi WK (2018) Pricing Lives: Guideposts for a Safer Society. (Princeton University Press, Princeton, NJ).

[10] The White House (2021) Fact Sheet: Biden-Harris Administration Announces Comprehensive Strategy to Prevent and Respond to Gun Crime and Ensure Public Safety.

[11] Theall KP, Shirtcliff EA, Dismukes AR, Wallace M, Drury SS (2017) Association Between Neighborhood Violence and Biological Stress in Children. JAMA Pediatrics 171(1):53-60.

[12] Rosenberg M, Ranapurwala SI, Townes A, Bengtson AM (2017) Do black lives matter in public health research and training? PLOS ONE 12(10):e0185957.

[13] Wrigley-Field E (2020) US racial inequality may be as deadly as COVID-19. Proceedings of the National Academy of Sciences 117(36):21854-21856.

[14] Currie E (2020) A Peculiar Indifference: The Neglected Toll of Violence on Black America. (Metropolitan Books, New York).

[15] National Research Council (2012) Social and Economic Costs of Violence: Workshop Summary. (National Academies Press, Washington, DC). 
[16] Edwards F, Lee H, Esposito M (2019) Risk of being killed by police use of force in the United States by age, race-ethnicity, and sex. Proceedings of the National Academy of Sciences 116(34):16793-16798. 

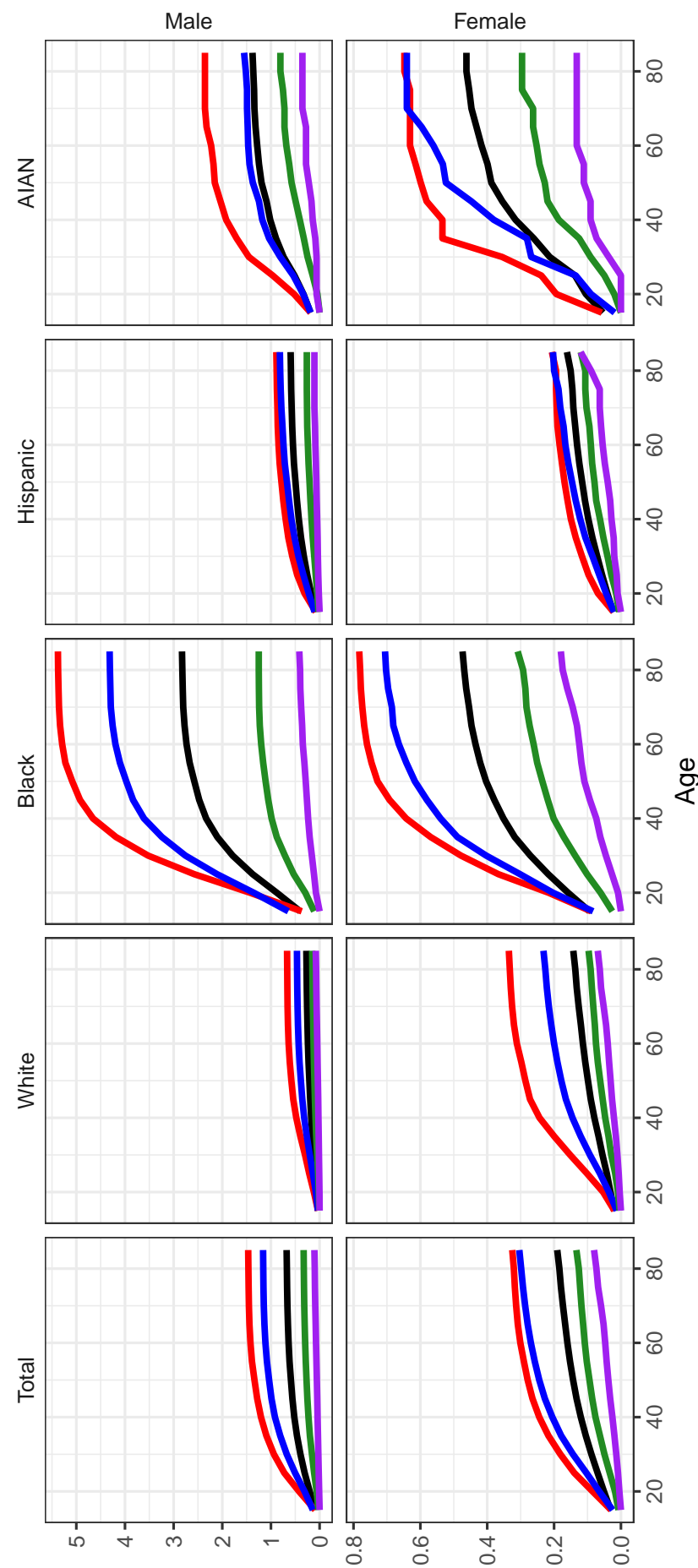

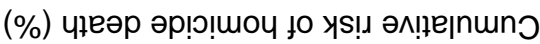

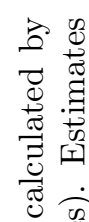

ส

亲势

言苗

工

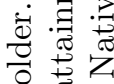

$-0$

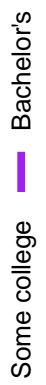

สี สี

늑.

\%

कo

की

范

क⿺辶大

. 즁

苟 蓬

$\because$

莳焉允

응

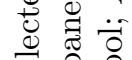

की 0

of

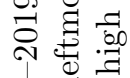

$\infty \doteq$

苓

की

要

范苍

월

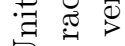

与

공

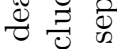

음

.

号

讪

出

击

它

节

U

-1.

它 


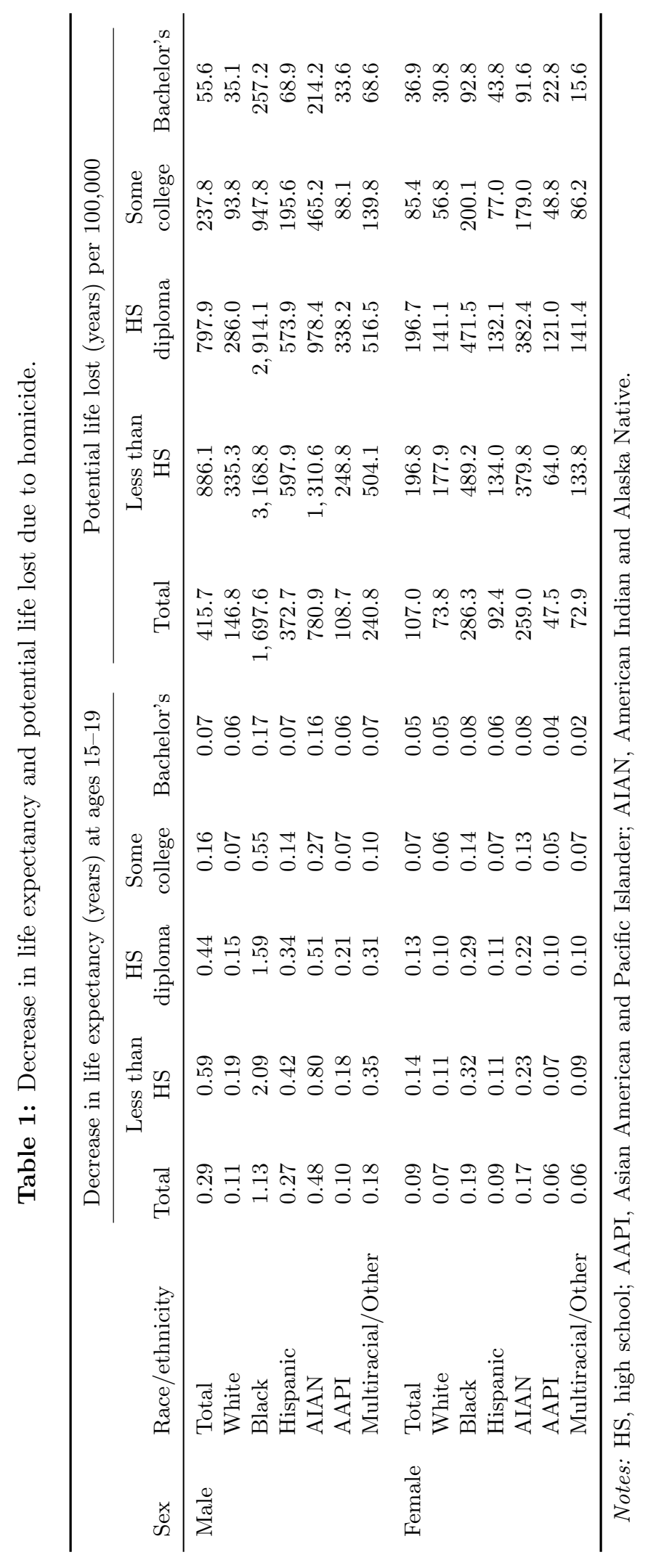




\section{Supporting Information Appendix: Extended Methods}

Inequality in Life Lost to Violence in the United States

Alexander F. Roehrkasse 


\section{Calculation of cumulative risk of homicide and non-homicide death}

The methods closely follow those described by Preston et al. [1]. I calculate multipledecrement synthetic-cohort life tables separately by sex, ethnoracial group, and education group, and use five-year age intervals except for ages $0,1-4$, and 85 and older. ${ }_{n} N_{x}$ is the mid-year population aged $x$ to $x+n$, measuring using American Community Survey (ACS) five-year samples [2]. ${ }_{n} D_{x}$ is the number of deaths occurring in the age interval, measured using mortality multiple cause files from the National Vital Statistics System [3]. For the master (single decrement) life table of deaths of all causes, ${ }_{n} a_{x}$ is the average number of years lived by those people dying in the interval: for age intervals 0 and 1-4 I use Coale-Demeny model West life tables [4], and for the remaining intervals I use values from Keyfitz and Flieger [5]. Then:

$$
\begin{aligned}
{ }_{n} m_{x} & =\frac{{ }_{n} D_{x}}{{ }_{n} N_{x}} ; \\
{ }_{n} q_{x} & =\frac{n \cdot{ }_{n} m_{x}}{1+\left(n-{ }_{n} a_{x}\right) \cdot{ }_{n} m_{x}}, \quad{ }_{\infty} q_{85}=1 ; \\
{ }_{n} p_{x} & =1-{ }_{n} q_{x} ; \\
l_{0} & =100,000, \quad l_{x+n}=l_{x} \cdot{ }_{n} p_{x} ; \\
{ }_{n} d_{x} & =l_{x}-l_{x+n} .
\end{aligned}
$$

For the multiple decrement life table, where ${ }_{n} D_{x}^{i}$ is the number of deaths in the age interval due to cause $i$ and $i=h$ indicates homicide deaths, cumulative risk of homicide death ${ }_{n} C_{x}^{h}$ (Figure 1) is calculated in percentage terms as:

$$
\begin{aligned}
{ }_{n} q_{x}^{h} & ={ }_{n} q_{x} \cdot \frac{{ }_{n} D_{x}^{h}}{{ }_{n} D_{x}} ; \\
{ }_{n} d_{x}^{h} & ={ }_{n} q_{x}^{h} \cdot l_{x} ; \\
{ }_{n} C_{x}^{h} & =\frac{\sum_{k=0}^{x} d_{k}^{h}}{100,000} \cdot 100 .
\end{aligned}
$$


Cumulative risk of non-homicide death ${ }_{n} C_{x}^{-h}$, referred to in the text, is calculated by substituting the count of deaths for all causes other than homicide ${ }_{n} D_{x}^{-h}$ for ${ }_{n} D_{x}^{h}$ in Equation 2, and recalculating Equations 3 and 4 accordingly.

\section{Calculation of cause-specific decreases in life expectancy}

Actual life expectancy $L E_{x}$ is calculated as:

$$
\begin{aligned}
{ }_{n} L_{x} & =n \cdot l_{x+n}+{ }_{n} a_{x} \cdot{ }_{n} d_{x} ; \\
L E_{x} & =\frac{\sum_{k=x}^{\infty} L_{k}}{l_{x}} .
\end{aligned}
$$

For homicide deaths and, for comparison, for other leading causes of death referred to in the text, I calculate cause-deleted life expectancy ${ }^{*} L E_{x}^{-i}$-in other words, life expectancy in the counterfactual scenario where no deaths due to cause $i$ occurred - using an associated single decrement life table, where:

$$
\begin{aligned}
R^{-i} & =\frac{{ }_{n} D_{x}-{ }_{n} D_{x}^{i}}{{ }_{n} D_{x}} ; \\
{ }_{n}^{*} p_{x}^{-i} & =\left[{ }_{n} p_{x}\right]^{R^{-i}} ; \\
{ }^{*} l_{0}^{-i} & =100,000, \quad{ }^{*} l_{x+n}^{-i}={ }^{*} l_{x}^{-i} \cdot{ }_{n}^{*} p_{x}^{-i} .
\end{aligned}
$$

After calculating ${ }_{n}^{*} d_{x}^{-i}$ by substituting ${ }^{*} l_{x}^{-i}$ in Equation 1, following Chiang [6]:

$$
{ }_{n}^{*} a_{x}^{-i}= \begin{cases}n+R^{i} \cdot \frac{{ }_{n} q_{x}}{1-{ }_{n}^{*} p_{x}^{-i}} \cdot\left({ }_{n} a_{x}-n\right), & x \in\{0,1,5,80\} \\ \frac{-\frac{5}{24}_{n}^{*} d_{x-5}^{-i}+2 .{ }_{n}^{*} d_{x}^{-i}+\frac{5}{24}{ }_{n}^{*} d_{x+5}^{-i}}{{ }_{n}^{*} d_{x}^{-i}}, & x \in\{10,15, \ldots, 75\} \\ \frac{L E_{85}}{R^{-i}}, & x=85 .\end{cases}
$$


Then, paralleling Equations 5 and 6:

$$
\begin{aligned}
{ }_{n}^{*} L_{x}^{-i} & =n \cdot{ }^{*} l_{x+n}^{-i}+{ }_{n}^{*} a_{x}^{-i} \cdot{ }_{n}^{*} d_{x}^{-i} \\
{ }^{*} L E_{x}^{-i} & =\frac{\sum_{k=x}^{\infty}{ }^{*} L_{k}^{-i}}{{ }^{*} l_{x}^{-i}}
\end{aligned}
$$

At ages 15-19, the first age interval for which all education groups are defined, the impact of a given cause of death on life expectancy (Table 1) is:

$$
{ }_{\Delta} L E_{15-19}^{i}={ }^{*} L E_{15-19}^{-i}-L E_{15-19} .
$$

\section{Calculation of years of potential life lost to homicide}

To control for variation in age structure across ethnoracial and educational groups, I calculate age-standardized years of potential life lost to homicide per 100,000 people (Table 1) as:

$$
Y P L L_{\text {standardized }}^{h}=\sum_{x=0}^{85}\left(\frac{{ }_{n} D_{x}^{h} \cdot\left({ }^{*} L E_{x}^{-h}-{ }_{n} a_{x}^{h}\right)}{{ }_{n} N_{x}} \cdot 100,000\right) \cdot{ }_{n} w_{x},
$$

where ${ }_{n} D_{x}^{h}$ is the number of homicide deaths between ages $x$ and $x+n ;{ }_{n} a_{x}^{h}$ is the time to homicide death within each age interval, assumed to be half the interval length for ages greater than 0 and calculated as 0.387 years for people aged less than one year [7]; ${ }_{n} N_{x}$ is the mid-year population aged $x$ to $x+n ;{ }_{n} w_{x}$ is the sex-specific proportion of U.S. residents aged $x$ to $x+n$; and $j$ is the lowest age for which each education group has a non-zero population [8].

Total years of life lost to homicide annually over 2018-2019, referred to in the text, are calculated as:

$$
Y P L L_{\text {total }}^{h}=\frac{\sum_{x=0}^{85}\left({ }_{n} D_{x}^{h} \cdot\left({ }^{*} L E_{x}^{-h}-{ }_{n} a_{x}^{h}\right)\right)}{2} .
$$




\section{Appendix References}

[1] Preston S, Heuveline P, Guillot M (2001) Demography: Measuring and Modeling Population Processes. (Blackwell Publishers, Oxford, UK).

[2] Ruggles S, et al. (2021) IPUMS USA: Version 11.0 [dataset]. (IPUMS, Minneapolis, $\mathrm{MN})$.

[3] National Center for Health Statistics (2021) Vital Statistics Online Data Portal.

[4] Coale AJ, Demeny P (1983) Regional Model Life Tables and Stable Populations. (Academic Press, New York), 2nd edition.

[5] Keyfitz N, Flieger W (1990) World Population Growth and Aging: Demographic Trends in the Late Twentieth Century. (University of Chicago Press, Chicago).

[6] Chiang CL (1968) An Introduction to Stochastic Processes in Biostatistics. (Wiley, New York).

[7] Centers for Disease Control and Prevention NCfHS (2020) Underlying Cause of Death 2018-2019 on CDC WONDER Online Database. http://wonder.cdc.gov/ucd-icd10.html.

[8] Aragón TJ, Lichtensztajn DY, Katcher BS, Reiter R, Katz MH (2008) Calculating expected years of life lost for assessing local ethnic disparities in causes of premature death. BMC Public Health 8(1):116. 